\title{
The effect of special training on some physical-skill requirements associated with the offensive performance of karate kumite players
}

\author{
Prof. Dr/ Youssef Dahab Ali \\ Prof. Dr/ Ahmed Mahmoud Ibrahim \\ Doctoral researcher/ Kholoud Hamdi Ali Ghazi
}

\section{Introduction and importance of the study :}

Choosing the appropriate material for practicing a specific sporting activity is the first step to excel in this activity, which requires the availability of special biological, physical and skill determinants in addition to the scientific training programs, as these determinants are the cornerstone of making the sports hero.

Karate is a competitive sport that requires special skillful physical abilities, and karate is characterized by defensive and offensive methods, and it is considered one of the best sports in self-defense. (4: 11)

Hence, scientific research and studies try to determine the most important physical and skill requirements that are required by the characteristics and nature of the practicing sports activity. It also positively affects the effectiveness of the training process to reach high sports levels, as selecting the talented individual to practice a specific sporting activity from the beginning leads to saving a lot of effort, money and even prediction the level of the player in the future.

And Ahmed Mahmoud Ibrahim (2005) indicated that the possibilities for the youngster to reach high levels in karate become effective if possible from the beginning to select the youngster and direct him to the competition that suits his various preparations and abilities and to predict according to the scientific foundations and standards the extent of the impact of training and practice processes on the development and development of those

preparations And the different capabilities in effective ways that enable the player to achieve continuous progress in the activity of the specialist. (2:7)

Karate is a Japanese sport, and it is one of the competitive sports that require special skillful physical abilities. Karate is characterized by defensive and offensive methods, and it is considered one of the best sports in self-defense. (4: 11)

\section{Purpose of the study:}

The study aims to identify the effect of training day planning directive on some physical and skill requirements of kumite players. 


\section{Imposition of the study:}

There are statistically significant differences between the values of pre and post measurement on some of the skillful physical requirements of kumite players.

\section{Study Approach:}

The researchers used the experimental approach using the one-group design with pre and post measurement.

\section{Fields of study:} Spatial domain:

The study was applied in the hall of the Faculty of Physical Education for Men - Alexandria University.

\section{The human domain:}

Egyptian national karate players under the age of 21 men. The study sample was deliberately chosen from the karate sport players specializing in the actual fighting competition 'comet' at the Olympic Sports Club, Victoria's Champions Club, Somuah Sports Club, and the Al-Jays Vanguards Club. The sample number for the study reached (6) players.

\section{Conditions for selecting the study sample are as follows:}

1- That the players are registered with the Egyptian Karate Sports Federation specializing in the actual fighting competition (kumite) in the Alexandria region.

2- That there be men within the Sunni stage.

3- The player must have won tournaments in the actual combat competition during the previous season to conduct the experiment.

\section{Basic experience:}

The basic experiment was applied during the period from (5/1/2019) to (7/3/2019) on the players under study, and the time period for the experiment was distributed in two phases as follows: -

Pre-measurement - Saturday 5/1/2019 to Thursday 10/1/2019 (physical - skill)

Implementation of the experiment (35 training units) from Saturday 12/1/2019 to Thursday 2/28/2019.

Post measurement - Saturday 2/3/2019 to Thursday 7/3/2019. 
Presentation and discussion of results: -

Table (1) illustrates the statistical treatment (T) and the significance of the differences between the mean scores of the sample values in the pre and post measurements of the variable 'force characterized by velocity' under study.

$$
n=6
$$

\begin{tabular}{|c|c|c|c|c|c|c|}
\hline Variables & Group & Average & $\begin{array}{l}\text { Standard } \\
\text { deviation }\end{array}$ & $\begin{array}{l}\text { Degree of } \\
\text { freedom }\end{array}$ & Value (t) & $\begin{array}{c}\text { Sig } \\
\text { P.value } \\
(0.05)\end{array}$ \\
\hline \multirow{2}{*}{$\begin{array}{c}\text { Short front straight punch } \\
\text { (Akzme - Suki) } \\
\text { R }\end{array}$} & Tribal & 18.66 & 0.51 & \multirow{2}{*}{5} & \multirow{2}{*}{3.79} & \multirow{2}{*}{0.01} \\
\hline & After me & 19.83 & 0.40 & & & \\
\hline \multirow{2}{*}{$\begin{array}{c}\text { Short front straight punch } \\
\text { (Akzme - Suki) } \\
\text { L }\end{array}$} & Tribal & 17.50 & 0.54 & \multirow{2}{*}{5} & \multirow{2}{*}{1.93} & \multirow{2}{*}{0.11} \\
\hline & After me & 18.50 & 0.83 & & & \\
\hline \multirow{2}{*}{$\begin{array}{c}\text { Corresponding straight punch } \\
\text { (Gecko-Suki) } \\
\text { R }\end{array}$} & Tribal & 20.16 & 0.40 & \multirow{2}{*}{5} & \multirow{2}{*}{3.11} & \multirow{2}{*}{0.01} \\
\hline & After me & 20.16 & 0.40 & & & \\
\hline \multirow{2}{*}{$\begin{array}{c}\text { Corresponding straight punch } \\
\text { (Gecko-Suki) } \\
\text { L }\end{array}$} & Tribal & 22.83 & 1.32 & \multirow{2}{*}{5} & \multirow{2}{*}{0.41} & \multirow{2}{*}{0.69} \\
\hline & After me & 23.00 & 0.63 & & & \\
\hline \multirow{2}{*}{$\begin{array}{c}\text { Short Forward Half-Round Kick } \\
\text { (Eczami - Mawashi - Jerry) } \\
\text { R }\end{array}$} & Tribal & 19.33 & 1.21 & \multirow{2}{*}{5} & \multirow{2}{*}{3.95} & \multirow{2}{*}{0.01} \\
\hline & After me & 21.00 & 1.09 & & & \\
\hline \multirow{2}{*}{$\begin{array}{c}\text { Short Forward Half-Round Kick } \\
\text { (Eczami - Mawashi - Jerry) } \\
\text { L }\end{array}$} & Tribal & 19.66 & 1.50 & \multirow{2}{*}{5} & \multirow[t]{2}{*}{4.53} & \multirow{2}{*}{0.00} \\
\hline & After me & 21.83 & 0.75 & & & \\
\hline \multirow{2}{*}{$\begin{array}{c}\text { The short opposite semi-circular kick } \\
\text { (Eczami - Ura - Mawashi - Jerry) } \\
\text { R }\end{array}$} & Tribal & 15.16 & 0.98 & \multirow{2}{*}{5} & \multirow[t]{2}{*}{3.16} & \multirow{2}{*}{0.02} \\
\hline & After me & 16.50 & 0.54 & & & \\
\hline \multirow{2}{*}{$\begin{array}{c}\text { The short opposite semi-circular kick } \\
\text { (Eczami - Ura - Mawashi - Jerry) } \\
\text { L }\end{array}$} & Tribal & 15.33 & 0.51 & \multirow{2}{*}{5} & \multirow[t]{2}{*}{4.39} & \multirow{2}{*}{0.00} \\
\hline & After me & 16.83 & 0.40 & & & \\
\hline
\end{tabular}

The tabular (v) value at the level of significance $0.05=1.22$ 


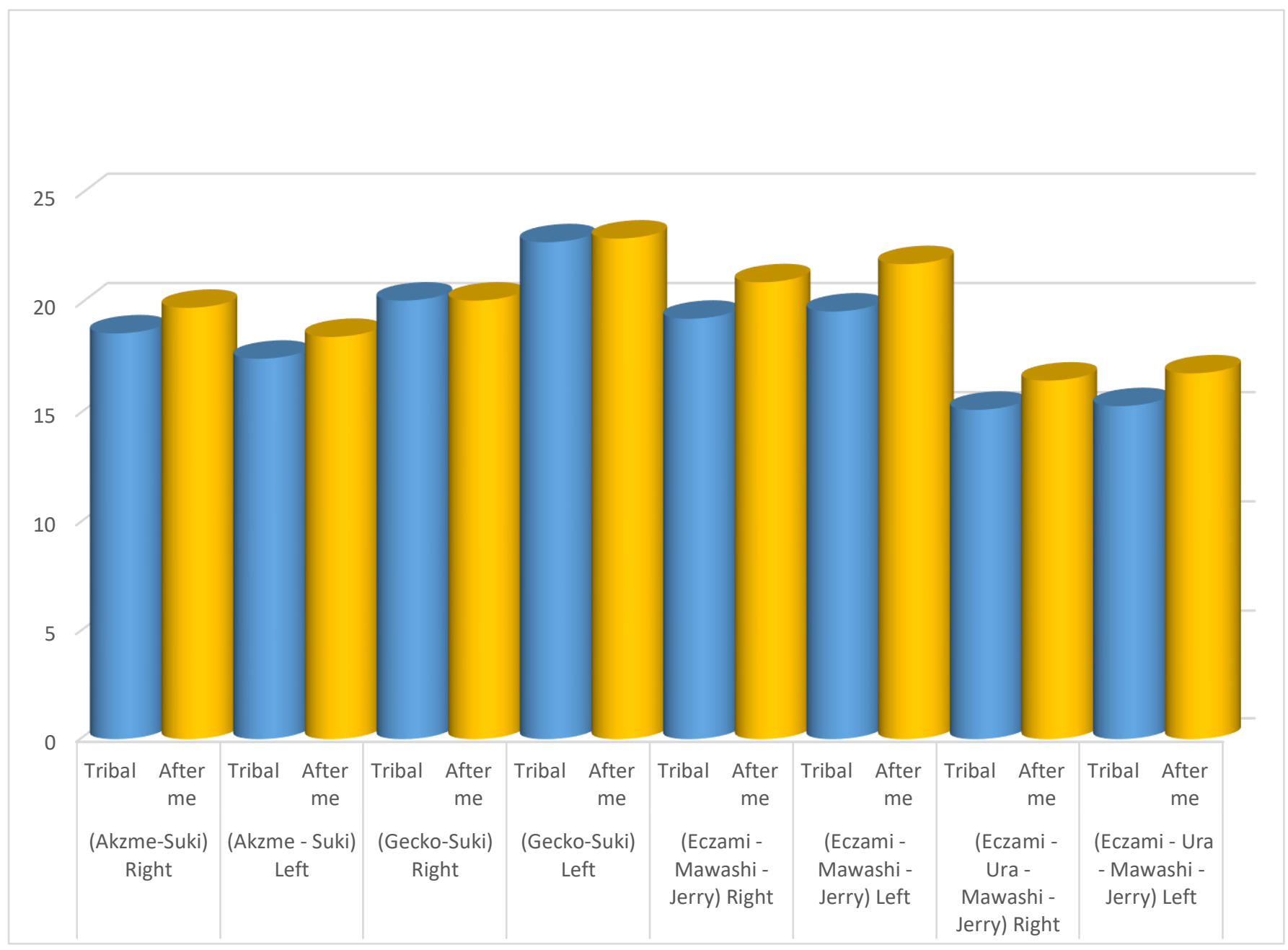

Tribal

After me

Figure No. (1) Average values of the pre and post measurement of the variable 'strength characteristic with speed' for the skill styles of the players under study.

Table No. (1) Shows that there are differences between the average values of the pre and post measurement of the variable 'strength characteristic by speed' for the skill methods of the players under study. 
Table (2) shows the statistics of ( $T$ ) and the significance of the differences between the mean scores of the sample values in the pre and post measurements of the variable 'velocity tolerance' under study

$\mathrm{n}=6$

\begin{tabular}{|c|c|c|c|c|c|c|}
\hline Variables & Group & Average & $\begin{array}{l}\text { Standard } \\
\text { deviation }\end{array}$ & $\begin{array}{l}\text { Degree of } \\
\text { freedom }\end{array}$ & Value $(t)$ & $\begin{array}{c}\text { Sig } \\
\text { P.value } \\
(0.05)\end{array}$ \\
\hline \multirow{2}{*}{$\begin{array}{c}\text { Short front straight punch } \\
\text { (Akzme - Suki) } \\
\text { R }\end{array}$} & Tribal & 37.16 & 0.98 & \multirow[b]{2}{*}{5} & \multirow{2}{*}{1.16} & \multirow{2}{*}{0.29} \\
\hline & After me & 36.66 & 0.51 & & & \\
\hline \multirow{2}{*}{$\begin{array}{c}\text { Short front straight punch } \\
\text { (Akzme - Suki) } \\
\text { L }\end{array}$} & Tribal & 36.50 & 0.54 & \multirow{2}{*}{5} & \multirow{2}{*}{0.00} & \multirow{2}{*}{1.00} \\
\hline & After me & 36.50 & 1.64 & & & \\
\hline \multirow{2}{*}{$\begin{array}{c}\text { Corresponding straight punch } \\
\text { (Gecko-Suki) } \\
\text { R } \\
\end{array}$} & Tribal & 40.66 & 1.21 & \multirow[b]{2}{*}{5} & \multirow[b]{2}{*}{7.74} & \multirow[b]{2}{*}{0.00} \\
\hline & After me & 42.66 & 1.21 & & & \\
\hline \multirow{2}{*}{$\begin{array}{c}\text { Corresponding straight punch } \\
\text { (Gecko-Suki) } \\
\text { L }\end{array}$} & Tribal & 42.33 & 1.63 & \multirow[b]{2}{*}{5} & \multirow{2}{*}{4.39} & \multirow[b]{2}{*}{0.00} \\
\hline & After me & 43.83 & 1.32 & & & \\
\hline \multirow{2}{*}{$\begin{array}{c}\text { Short Forward Half-Round Kick } \\
\text { (Eczami - Mawashi - Jerry) } \\
\text { R }\end{array}$} & Tribal & 29.66 & 3.44 & \multirow{2}{*}{5} & \multirow{2}{*}{3.65} & \multirow{2}{*}{0.01} \\
\hline & After me & 33.66 & 1.21 & & & \\
\hline \multirow{2}{*}{$\begin{array}{c}\text { Short Forward Half-Round Kick } \\
\text { (Eczami - Mawashi - Jerry) } \\
\text { L }\end{array}$} & Tribal & 31.66 & 2.33 & \multirow[b]{2}{*}{5} & \multirow{2}{*}{10.30} & \multirow{2}{*}{0.00} \\
\hline & After me & 34.83 & 2.31 & & & \\
\hline \multirow{2}{*}{$\begin{array}{c}\text { The short opposite semi-circular kick } \\
\text { (Eczami - Ura - Mawashi - Jerry) } \\
\text { R }\end{array}$} & Tribal & 19.83 & 1.83 & \multirow{2}{*}{5} & \multirow{2}{*}{3.10} & \multirow{2}{*}{0.02} \\
\hline & After me & 22.83 & 0.98 & & & \\
\hline \multirow{2}{*}{$\begin{array}{l}\text { The short opposite semi-circular kick } \\
\text { (Eczami - Ura - Mawashi - Jerry) } \\
\text { L }\end{array}$} & Tribal & 22.00 & 1.09 & \multirow{2}{*}{5} & \multirow{2}{*}{2.71} & \multirow{2}{*}{0.04} \\
\hline & After me & 23.66 & 1.03 & & & \\
\hline
\end{tabular}

The tabular (v) value at the level of significance $0.05=1.22$ 


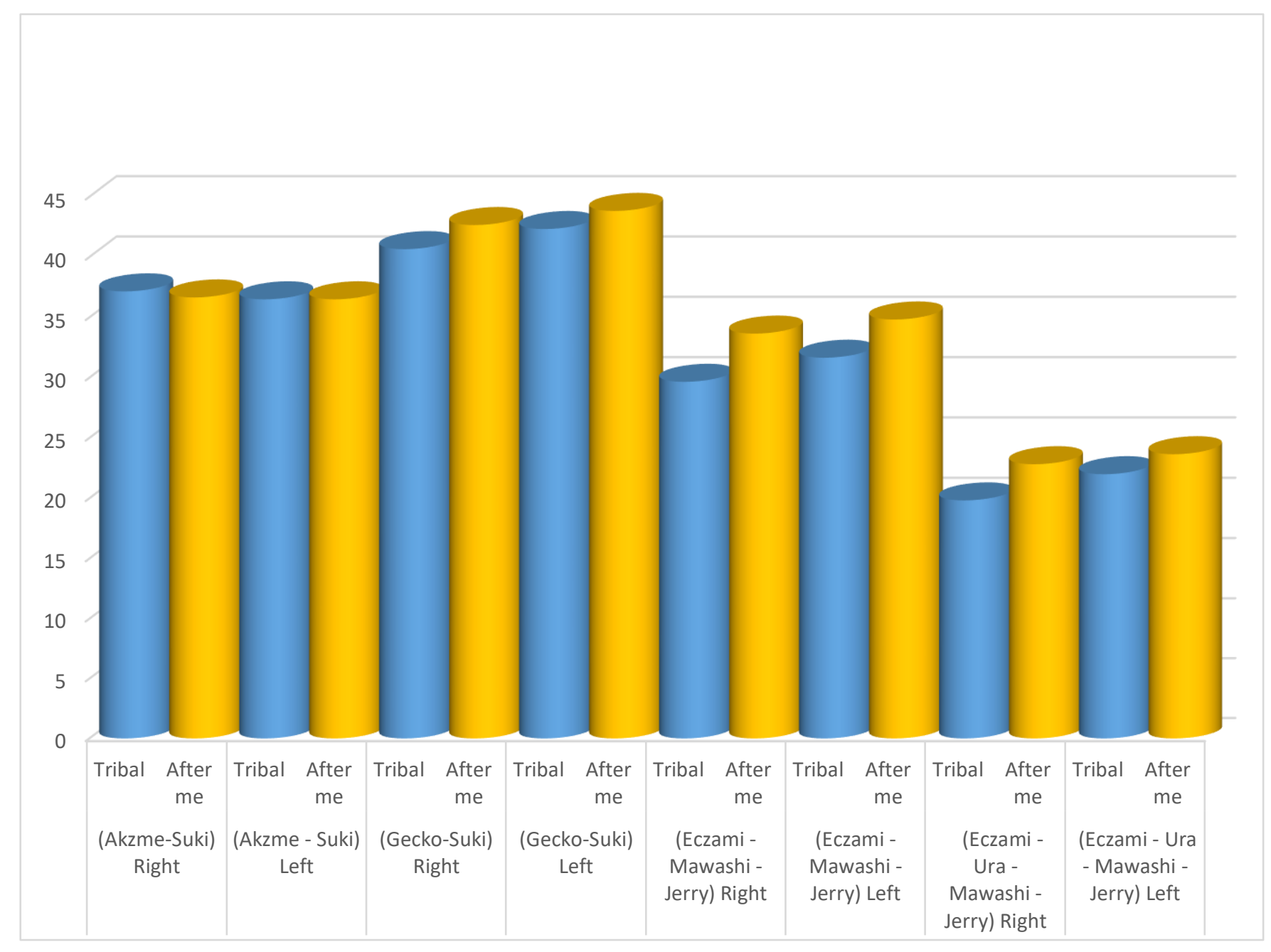

Tribal

After me

Figure No. (2) Average values of the pre and post measurement of the variable 'speed tolerance' for the skill styles of the players under study.

Table No. (2) Shows that there are differences between the tribal and dimensional measurements of the variable 'bearing velocity' of the skill styles of the players under study. 
Table (3) shows the statistical treatment (T) and the significance of the differences between the mean scores of the sample values in the pre and post measurements of the variable 'performance tolerance' under study $\mathrm{n}=6$

\begin{tabular}{|c|c|c|c|c|c|c|}
\hline Variables & Group & Average & $\begin{array}{l}\text { Standard } \\
\text { deviation }\end{array}$ & $\begin{array}{l}\text { Degree of } \\
\text { freedom }\end{array}$ & Value (t) & $\begin{array}{c}\text { Sig } \\
\text { P.value } \\
(0.05)\end{array}$ \\
\hline \multirow{2}{*}{$\begin{array}{c}\text { Short front straight punch } \\
\text { (Akzme - Suki) } \\
\text { R }\end{array}$} & Tribal & 80.66 & 1.03 & \multirow[b]{2}{*}{5} & \multirow[b]{2}{*}{0.30} & \multirow[b]{2}{*}{0.77} \\
\hline & After me & 80.83 & 1.32 & & & \\
\hline \multirow{2}{*}{$\begin{array}{c}\text { Short front straight punch } \\
\text { (Akzme - Suki) } \\
\text { L }\end{array}$} & Tribal & 78.16 & 0.98 & \multirow{2}{*}{5} & \multirow{2}{*}{0.34} & \multirow{2}{*}{0.74} \\
\hline & After me & 78.00 & 1.54 & & & \\
\hline \multirow{2}{*}{$\begin{array}{c}\text { Corresponding straight punch } \\
\text { (Gecko-Suki) } \\
\text { R }\end{array}$} & Tribal & 95.00 & 1.09 & \multirow[b]{2}{*}{5} & \multirow[b]{2}{*}{1.51} & \multirow[b]{2}{*}{0.19} \\
\hline & After me & 96.33 & 1.63 & & & \\
\hline \multirow{2}{*}{$\begin{array}{c}\text { Corresponding straight punch } \\
\text { (Gecko-Suki) } \\
\text { L }\end{array}$} & Tribal & 86.50 & 1.64 & \multirow{2}{*}{5} & \multirow{2}{*}{3.78} & \multirow{2}{*}{0.01} \\
\hline & After me & 89.33 & 0.81 & & & \\
\hline \multirow{2}{*}{$\begin{array}{c}\text { Short Forward Half-Round Kick } \\
\text { (Eczami - Mawashi - Jerry) } \\
\text { R }\end{array}$} & Tribal & 54.50 & 2.58 & \multirow{2}{*}{5} & \multirow{2}{*}{1.95} & \multirow{2}{*}{0.10} \\
\hline & After me & 58.33 & 5.75 & & & \\
\hline \multirow{2}{*}{$\begin{array}{c}\text { Short Forward Half-Round Kick } \\
\text { (Eczami - Mawashi - Jerry) } \\
\text { L }\end{array}$} & Tribal & 55.00 & 4.38 & \multirow{2}{*}{5} & \multirow{2}{*}{1.65} & \multirow{2}{*}{0.15} \\
\hline & After me & 57.00 & 3.89 & & & \\
\hline \multirow{2}{*}{$\begin{array}{c}\text { The short opposite semi-circular kick } \\
\text { (Eczami - Ura - Mawashi - Jerry) } \\
\text { R }\end{array}$} & Tribal & 50.16 & 1.47 & \multirow{2}{*}{5} & \multirow{2}{*}{2.71} & \multirow{2}{*}{0.04} \\
\hline & After me & 51.83 & 0.75 & & & \\
\hline \multirow{2}{*}{$\begin{array}{c}\text { The short opposite semi-circular kick } \\
\text { (Eczami - Ura - Mawashi - Jerry) } \\
\text { L }\end{array}$} & Tribal & 50.00 & 2.19 & \multirow{2}{*}{5} & \multirow{2}{*}{1.63} & \multirow{2}{*}{0.16} \\
\hline & After me & 51.66 & 1.21 & & & \\
\hline
\end{tabular}

The tabular ( $v$ ) value at the level of significance $0.05=1.22$ 


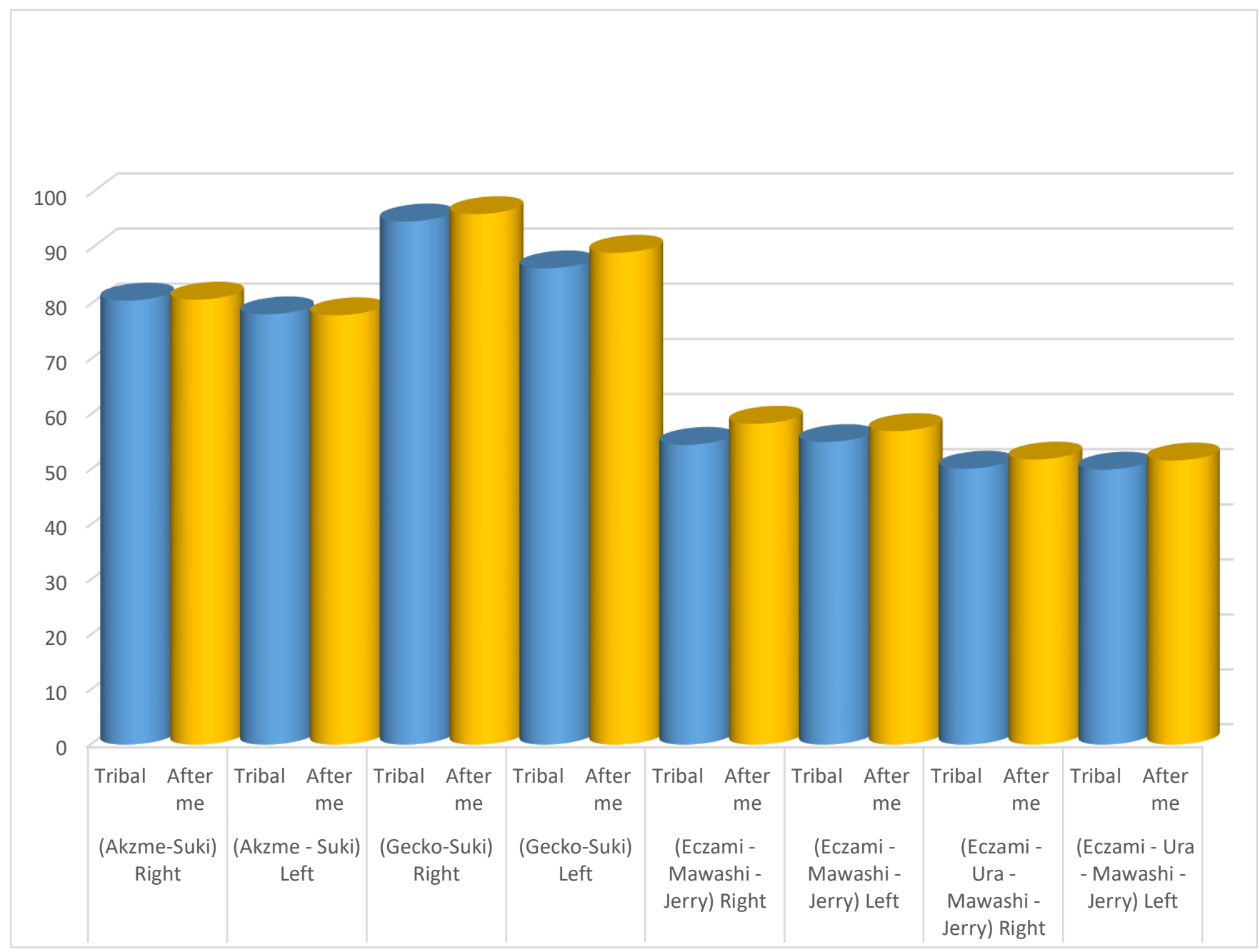

Tribal

After me

Figure No. (3) Average values of the pre and post measurement of the variable 'performance tolerance' for the skill styles of the players under study.

Table No. (3) Shows that there are differences between the tribal and dimensional measurements of the variable 'performance tolerance' of the skill styles of the players under study.

It is also evident from the data of Table (1-3) that there is an effect on the development of the values of the physical-skill requirements under study for the offensive activity. The researchers refer to the application of the characteristics of the interval training method in the parallel method with the specialization in choosing exercises similar to the nature of skill performance within the training content with rationing and implementation. It has the training stations in the 
training unit, training it individually and enjoys privacy in implementation and selection according to the playing positions during the main part of the training unit, in addition to distributing the training load to the player in privacy and individuality, and thus coincided with the player's acceptance of the daily training load in a better way and its contents. That is with what was indicated by each of $(1,3,4,5,6,7,8)$.

\section{The conclusion:-}

In light of presenting and discussing the results and within the limits of the study sample and the method used, the researchers were able to reach the following conclusions:

1- Special exercises affected the values of the skill physical requirement 'distinctive strength with speed' among kumite karate players.

2- Special exercises affected the values of the physical skill requirement 'endurance of speed' among kumite karate players.

3- Special exercises affected the values of the physical skill requirement 'endurance performance' among kumite karate players.

\section{Recommendations:-}

Through the conclusions reached by the researchers, they recommend the following: -

1- They recommend to be guided by the style and nature of the method used for the training loads under study.

2- Conducting more scientific research and studies dealing with other age stages, in order to rationalize them during the selection, training and evaluation processes.

\section{References:-}

1) Abu Al-Ela Ahmed Abdel-Fattah: Hospitalization in the Sports Field, House of Arab Thought, First Edition, Cairo, 1999.

2) Abu Al-Ela Ahmad Abdel-Fattah: Muhammad Sushi Hasaean: Physiology and Morphology of Sport and Measurement Methods for Orthodontics, First Edition, Dar AlFikr Al-Arabi, Cairo, 1997

3) Abrar Hussain Karon Abdel-Sayed: The effect of planning a multi-unit training day according to the indicators of the two types of biorhythm on the quantitative level of the determinants of the offensive activity of the players of the Comate Actual Fighting Competition '2017, unpublished PhD thesis, Faculty of Physical Education for Boys, Alexandria University. 
4) Ahmed Mahmoud Ibrahim: Methods of analysis and rationing of training loads for tactical maps for players of the 'kumite' actual combat competition, Malaria facility, Alexandria, 2015.

5) Ahmed Mahmoud Mohamed Ibrahim (2016): The effect of using biorhythm curves to direct the training loads of the opposite pillar as a tactical method against the competitor at the level of some determinants of the counter-offensive behavior of the kumite players in karate sport, the Seventh International Scientific Conference, Faculty of Physical Education for Girls in the island, Helwan University.

6) Iman Rashad Khalil (2015): The effect of using monthly biorhythm curves as a guide for training loads for me. Some of the determinants of my offensive activity for the female athletes of the actual fight competition 'Kroji' in Taekwondo, International Journal of Sports Science and Arts 'on line', College of Physical Education for Girls Helwan University, Egypt.

7) Ali Fahmi Al-Baik: Sports Training Load (General, Swimming), Al-Shorouk Press, Cairo, 1984.- Muhammad Abdel-Rahman Ali (2015): The effect of directing proposed training loads using dynamic rhythm on some determinants of offensive activity for players of actual combat in karate sport, International Journal of Sports Science and Arts on line Faculty of Physical Education for Girls, Helwan University, Egypt, 2015.

8) Walaa Hamdi Farghali Abdel Hamid: The effect of using tactical maps on the level of quantitative effectiveness of some determinants of the offensive activity of the players of the actual fighting competition 'kumite' in karate. Unpublished MA Thesis, College of Physical Education for Women, Helwan University, 2014. 


\title{
Abstract:- \\ The effect of special training on some physical-skill requirements associated with the offensive performance of karate kumite players
}

\author{
Prof. Dr/ Youssef Dahab Ali \\ Prof. Dr/ Ahmed Mahmoud Ibrahim \\ Doctoral researcher/ Kholoud Hamdi Ali Ghazi
}

\section{Introduction and importance of the study :}

Hence, scientific research and studies try to determine the most important physical and skill requirements that are required by the characteristics and nature of the practicing sports activity. It also positively affects the effectiveness of the training process to reach high sports levels, as selecting the talented individual to practice a specific sporting activity from the beginning leads to saving a lot of effort, money and even prediction the level of the player in the future.

\section{Purpose of the study:}

The study aims to identify the effect of training day planning directive on some physical and skill requirements of kumite players.

The researchers used the experimental approach using the one-group design with pre and post measurement- The study was applied in the hall of the Faculty of Physical Education for Men - Alexandria University- Egyptian national karate players under the age of 21 men. The study sample was deliberately chosen from the karate sport players specializing in the actual fighting competition 'comet' at the Olympic Sports Club, Victoria's Champions Club, Somuah Sports Club, and the Al-Jays Vanguards Club. The sample number for the study reached (6) players - It is also evident from the data is an effect on the development of the values of the physical-skill requirements under study for the offensive activity. The researchers refer to the application of the characteristics of the interval training method in the parallel method with the specialization in choosing exercises similar to the nature of skill performance within the training content with rationing and implementation. It has the training stations in the training unit, training it individually and enjoys privacy in implementation and selection according to the playing positions during the main part of the training unit, in addition to distributing the training load to the player in privacy and individuality, and thus coincided with the player's acceptance of the daily training load in a better way and its contents. 